\title{
Políticas como tradução: situando as políticas sociais transnacionais*
}

\section{Policies as translation: situating the transnational social policies}

\author{
Noémi Lendvai** $^{* *}$ \\ Paul Stubbs ${ }^{* * *}$
}

\begin{abstract}
Resumo: Este trabalho explora algumas das implicações do desenvolvimento de uma antropologia ou etnografia das dimensões transnacionais da política. A primeira parte explica o aparato conceitual básico, em termos de política como criadora de significados. A segunda parte examina a política como tradução e explora suas implicações em termos de transnacionalização das políticas e, em particular, procura contrastar a tradução de políticas com noções mais ortodoxas de transferência de políticas. A terceira parte explora a tradução de políticas através de uma abordagem etnográfica reflexiva, desenvolvendo alguns casos baseados no envolvimento prático dos autores em reformas de políticas sociais em partes da Europa Central e do Leste. A quarta parte apresenta algumas conclusões e indica algumas objeções teóricas e éticas que podem e devem ser levantadas com relação à abordagem apresentada.
\end{abstract}

Palavras-chave: Política educacional. Políticas sociais. Trasnacionalização.

\begin{abstract}
This article explores some of the implications of the development of an anthropology or ethnography of the transnational dimensions of policies. The first part explains the basic conceptual apparatus, in terms of policies as a generator of meanings. The second part examines policies as translation and explores its implications in terms of the transnationalization of the policies and, in particular, it seeks to contrast the translation of policies with more orthodox knowledge of policies transference. The third part explores the translation of policies through a reflexive ethnographical approach, analyzing a number of cases based on the practical involvement of the authors in social policies reforms in regions of the Central Europe and the East. The fourth part presents some conclusions and indicates certain theoretical and ethical objections that can and must be raised with regard to the presented approach.

Keywords: Education policies. Social policies. Transnationalization.

\footnotetext{
Texto inicialmente publicado no livro Policy reconsidered: meanings, politics and practices, organizado por Susan M. Hodgson e Zoë Irving (The Policy Press, 2007, p. 173-189). Artigo traduzido e publicado com autorização dos autores e da Editora The Policy Press - University of Bristol. A equipe editorial da Revista Práxis Educativa agradece aos autores e à editora The Policy Press pela autorização. Tradução de Silvana Aparecida Carvalho do Prado. Revisão técnica de Jefferson Mainardes (PPGE/UEPG) e Márcia dos Santos Ferreira (PPGE/UFMT).

** Professora do Instituto de Estudos Sociais e Europeus (Hungria) e University of Bristol.

E-mail: <noemi.lendvai@bristol.ac.uk>

*** Professor do Instituto de Economia (Croácia). E-mail: <pstubbs@eizg.hr>
} 


\section{Introdução}

Uma antropologia política construtivista "trata os modelos e a linguagem dos tomadores de decisão como dados etnográficos a serem analisados" (SHORE; WRIGHT, 1997, p. 13) de forma que a política seja vista mais como um processo do que como um fato. A abordagem aqui apresentada está mais preocupada com a questão de como a política cria significado ao invés de $o$ que a política significa. É o reverso de uma antropologia tradicional, que busca "tornar o estranho familiar", e assume o compromisso de "tornar o familiar estranho" (MacCLANCEY, 2002, p. 7). Acrescente-se a isso, que a política se internacionalizou, com importantes arenas de criação situadas em níveis que vão além do estado-nação; a política, também, se transnacionalizou, uma vez que os seus modelos e estruturas viajam através do tempo e lugar; e, até mesmo, se globalizou, através das condicionalidades formais das instituições financeiras internacionais e do poder "difuso" das "redes globais de políticas públicas" (STONE, 2003). Este capítulo, essencialmente, explora algumas das implicações do desenvolvimento de uma antropologia ou etnografia das dimensões transnacionais da política, ou seja, aquelas dimensões que abrangem os níveis que vão além do estado-nação tomado individualmente.

O enquadramento teórico empregado baseia-se na noção de política transnacional não como transferência, mas, ao invés disso, como tradução. O tema é tratado contextualmente em termos do nosso próprio trabalho de compreensão das mudanças nas "políticas sociais" em diversos países pós-comunistas em transição na Europa Central e do Leste como um local que passou por uma década e meia de dramática, embora talvez não única, "hiperinflação simbólica" de "símbolos, metáforas, linguagens e emblemas" (SCOTT, 2002). Uma arquitetura conceitual complexa emergiu, sob a égide da "reforma", construída no encontro com entidades supranacionais, incluindo a União Europeia, o Banco Mundial, as Nações Unidas e suas agências, bem como em e através de encontros com uma variedade de atores internacionais não estatais, incluindo ONGs internacionais e empresas de consultoria privadas.

Neste sentido, nosso trabalho é parte de uma tradição emergente de pesquisa sobre política social internacional que substitui uma noção de atores internacionais todo-poderosos, por uma compreensão muito mais complexa, contextualmente enraizada, das interações que se dão dentro e entre os atores nacionais e supranacionais. Os relatos etnográficos dos processos de mudanças na política enfatizam a mediação, o diálogo, a tradução, o compromisso e a resistência. Nós focalizamos a política social em termos de suas "incertezas profundas" ou "deslocamentos" daquilo que é tido como certo (RUSTIN; FREEMAN, 1999, p. 12), no contexto de uma nova internacionalização, na qual os países comparam suas 
políticas sociais com as de outros países e na qual as noções de "política social europeia" e até mesmo de "política social global" sugerem modelos de reforma e referências que estão além daqueles do estado-nação.

A primeira parte deste capítulo explica o aparato conceitual básico, em termos de política como criadora de significados. A segunda parte examina a política como tradução e explora as implicações disto em termos de transnacionalização das políticas e, em particular, procura contrastar a tradução de políticas com noções mais ortodoxas de transferência de políticas. A terceira parte explora a tradução de políticas através de uma abordagem etnográfica reflexiva, desenvolvendo alguns casos baseados em nosso próprio envolvimento prático, e entendimento intelectual sobre reforma de políticas sociais em partes da Europa Central e do Leste. A quarta parte traz algumas conclusões breves e observa algumas objeções teóricas e éticas que podem e devem ser levantadas com relação à nossa abordagem.

Nosso trabalho é um encontro entre dois estudiosos, viajando entre os locais e através das fronteiras disciplinares. Um de nós (NL) é uma húngara que vive e trabalha no Reino Unido, o outro (PS) é um britânico, vivendo e trabalhando na Croácia. Educados em tradições de política social e administração social mais empíricas e normativas e, nós temos, cada um a seu modo, lutado para encontrar nossas vozes antropológicas e explorar novas relações entre pesquisa e práxis como parte de um processo de reavaliação de nosso próprio trabalho sobre globalização, europeização e política social na Europa Central e do Leste.

\section{Política como criadora de significados}

Definir política como um processo de criação de significados é reconhecer que a política está sempre "assentada em significados implícitos" (INNES, 2002) o que envolve, nas palavras de Stone, "uma luta discursiva constante sobre as definições dos problemas, dos limites de categorias usados para descrevêlos, os critérios para sua classificação e avaliação, e os significados de ideais que guiam determinadas ações" (STONE, 2002, p. 60). Em certo sentido, as políticas são sempre processos de criação de significados e de reivindicações (YANOW, 1996), que tem que ser "estudados do início ao fim" em termos de "rastreamento de discursos, prescrições e programas políticos e suas ligações com os afetados pelas políticas" (WEDEL, 2005, p. 37). Em outras palavras, perturbações interessantes, e às vezes até mesmo surpreendentes, podem ocorrer nos espaços entre a "criação", a "transmissão" e a "interpretação" ou "recepção" dos significados das políticas.

A política, nas palavras de Fischer (2003, p. 43), "não é apenas expressa em palavras, ela é literalmente "construída" através da linguagem que a descreve". 
Nós iríamos além desta noção "descritiva" de linguagem para afirmar que a política é registrada através da linguagem e não pode existir fora da linguagem. Entretanto, isto nunca é neutro ou técnico, pelo contrário, Bourdieu e Wacquant (1992, p. 142-143) afirmam:

as relações linguísticas são sempre relações de poder simbólico através das quais as relações de força entre os falantes e seus respectivos grupos são concretizadas de uma forma transfigurada. Consequentemente, é impossível elucidar qualquer ato de comunicação circunscrito apenas ao alcance da análise linguística. Mesmo o mais simples intercâmbio linguístico traz à tona uma rede complexa e ramificada de relações históricas de poder entre o falante, dotado de uma autoridade social específica, e uma audiência, que reconhece esta autoridade em diversos graus, bem como entre os grupos aos quais respectivamente eles pertencem.

Bourdieu e Wacquant (1992, p. 143) sugerem que as relações linguísticas são "ininteligíveis" fora da "totalidade das estruturas das relações de poder" embora se, como eles sugerem, estas são geralmente invisibilizadas nas trocas linguísticas é uma questão mais ampla, particularmente no caso dos encontros e discursos da política transnacional. Para Yanow (1996, p. 8-9), a política é fundamentalmente um processo interpretativo, que "se concentra nos significados das políticas, nos valores, sentimentos, e/ou crenças que elas expressam, e nos processos pelos quais tais significados são comunicados para e "lidos" por várias audiências". Em seu trabalho, ela demonstra convincentemente como o significado da política nunca é singular, mas sempre plural e contestado, envolvendo uma "leitura ativa" de vários atores políticos e públicos políticos relevantes, que são tanto intérpretes como criadores de "novos" significados. A política neste sentido é sempre múltipla e modificadora, transformando tanto o conteúdo como o contexto da política, da formação à implementação.

Em diversos idiomas, incluindo todas as línguas eslavas e o húngaro, uma mesma palavra geralmente serve tanto para a palavra inglesa politics (de política partidária) quanto para policy (de plano de ação). Recentemente, em croata, a palavra politika para policy foi parcialmente substituída pela palavra mjere (literalmente "medidas") para contemplar a diferença entre policy e politics. Além disso, a palavra policy é quase inevitavelmente qualificada por outras palavras, como: política pública, política social, política familiar, política de controle de armamento, política de igualdade de oportunidades, entre outras. Isto sugere que a palavra policy é, por si só, insuficiente para "mapear" ou "enquadrar" o que está sendo discutido. É claro que a criação de significado nas políticas nunca é um processo apolítico ou técnico, embora um grupo de "criadores de políticas" e "conselheiros" queiram sugerir que este é o caso. Como Shore e Wright já argumentaram, a natureza política das políticas é frequentemente "disfarçada 
por expressões objetivas, neutras, racionais-legais pelas quais são retratadas" (SHORE; WRIGHT, 1997, p. 8).

Vital para isto é a atribuição de expertise e de "conhecimento especializado" ao processo de tomada de decisão política. Enquanto um amplo corpo de trabalhos sobre "governabilidade" aponta para o papel do especialista na fixação de subjetividades, os perigos disso se tornar um pouco mais do que a "acumulação funcionalista de anedotas elaboradas para a confirmação de premissas revestidas de uma roupagem conceitual uniforme" (GOULD, 2005), são muito reais. Por esta razão, enquanto continuamos a enfatizar a importância das tecnologias políticas, incluindo a estatística, padrões, contratos, termos de referência, estruturas lógicas e similares, insistimos na especificidade histórica e contextual destas tecnologias. Talvez de forma ainda mais importante, nós temos um grande interesse na complexidade dos "domínios especializados" e na capacidade criativa dos "especialistas" para lidar com a "contradição, exceção [e] fatos que são efêmeros” (HOLMES; MARCUS, 2005, p. 237).

\section{Tradução de políticas e o transnacional: além da transferência de políticas}

A tradução, como um conceito, viajou um longo caminho desde suas origens na linguística e estudos de tradução, até uma situação na qual "hoje um crescente número de estudiosos estão conscientes tanto da complexidade conceitual como do significado político-ético da tradução", em termos de sua "cumplicidade com", ou, como preferimos, inseparabilidade da "construção, transformação ou interrupção das relações de poder” (SAKAI, 2006, p. 71-72). A sociologia da tradução vem, de longa data, enfatizando a natureza fluida e dinâmica da "política", onde os significados são constantemente transformados, traduzidos, distorcidos e modificados (LATOUR, 2005).

A noção de tradução problematiza a política, que é vista como um processo contínuo de deslocamento, perturbação, transformação e negociação (CALLON, 1986). A "tradução" ocorre em teias complexas de atores sociais e actantes $^{1}$ não sociais, chamadas de redes de atores, porque tudo e todos os envolvidos na rede são membros ativos e mediadores que dão forma e transformam as afirmações, os artefatos, os discursos e as interpretações de acordo com seus diferentes projetos (LATOUR, 1987), "equiparando-se ativamente e até mesmo deslocando os projetos das autoridades políticas" (O’MALLEY, 1996, p. 316). A tradução pode ser vista como "um processo contínuo pelo qual os indivíduos

\footnotetext{
${ }^{1}$ Latour (2000) define “actant” como qualquer coisa ou pessoa que na tradução precisa ser representada por porta-vozes. Por ser desprovida de voz, outro ator assumirá o papel de porta-voz. (LATOUR, B. Ciência em ação: como seguir cientistas e engenheiros sociedade afora. São Paulo: UNESP, 2000). (Nota de tradução).
} 
transformam o conhecimento, as verdades e os efeitos do poder cada vez que os encontram" (HERBERT-CHESHIRE, 2003, p. 456).

Um artigo não publicado de Richard Freeman é o que mais se aproxima de nosso próprio sentido do uso da "política como tradução". Para ele, a tradução transfere e transforma: ela implica em representar algo de uma nova maneira e em um novo lugar, inevitavelmente mudando o que isto significa. É uma "arte do comprometimento", uma arte não uma ciência, e implica mediação entre diferentes reivindicações. Acima de tudo, é mais do que uma interpretação: ela é ativa, produtiva e criativa (FREEMAN, 2004).

A tradução é, então, o trabalho real do poder. Na teoria pós-colonial, reconhecendo-se que a raiz do significado de "traduzir" é "conquistar" (KIBERD, 1995, p. 624), de forma que a "tradução cultural" é um lugar significativo de uma "reorganização dos mundos" (LOOMBA, 1998, p. 101), há um foco na representação, poder e historicidade (NIRANJANA, 1992). A sociologia da tradução considera as formas particulares pelas quais objetos, conhecimento e fatos são produzidos através do deslocamento ou da supressão de vozes contraditórias, ou daqueles "fatos impróprios para tornarem-se apropriados" (GEBHARDT, 1982, p. 405, grifo nosso). Um texto recente de Rada Ivekovic sugere que negligenciar a tradução pode contribuir para o "fechamento prematuro de histórias alternativas" e "para a supressão da diversidade, ao construir intraduzibilidade e incompreensão, que forçam a separação entre os idiomas relacionados: construindo "o outro" e esforçando-se por expulsá-lo para fora do "sistema", ou fora do "mundo bom" (IVEKOVIC, 2005, p. 1). A autora contrasta tradução e diálogo, onde o último implica uma dicotomia simétrica e esconde a hierarquia, enquanto a primeira é uma forma de resistência "às linhas hegemônicas da imposição do significado" (IVEKOVIC, 2005, p. 1). Em um sentido amplo, a tradução é usada como um dispositivo de sensibilização, enfatizando as travessias de significado e relações de poder que a prática da tradução encerra. Monaci e Caselli explicam a tradução como:

[...] resultado de um conjunto interligado de processos sociais e materiais, que ocorrem dentro de uma rede de relações e que modificam o conhecimento em cada estágio. Contrária à visão difusionista do processo de transferência de conhecimento, semelhante ao contágio por um vírus ou ao fluxo de eletricidade, a metáfora da tradução sugere que a produção, circulação e difusão de conhecimento entre os diferentes contextos sócio-culturais deveriam ser analisadas pela investigação de como seus usuários mudam suas atitudes cognitivas e normativas; também é enfatizado o papel das categorias culturais daqueles que "atuam e implementam" e trazem à existência o conhecimento transferido aos contextos locais de aplicação ao mobilizar, mediar, distorcer, expor, ignorar e, desta forma, recriar o conhecimento. (MONACI; CASELLI, 2005, p. 56, grifo nosso). 
John Clarke (2005b) considera a tradução como uma visão metafórica útil dentro de três importantes práticas políticas. Primeiro, a tradução ilumina alguns processos de difusão de políticas e de transferências de políticas em formas transnacionais. Aqui ele argumenta que "a dominação anglofônica da experiência política e das redes de políticas, as passagens de conceitos dentro e fora do 'inglês da política' pode ser um local de articulação e variação significativas" (CLARKE, 2005b, p. 8). Segundo, a tradução lança nova luz sobre a implementação, ou como as políticas se movem da formação de políticas à "linha de frente" da prática. Finalmente, ele afirma que a tradução, como uma estrutura conceitual, pode chamar atenção de fato tornar visível o trabalho dos tradutores, agentes e mediadores, "aqueles agentes translocais que mediam linguagens, contextos, locais e níveis" (CLARKE, 2005b, p. 8; LENDVAI; STUBBS, 2006).

O transnacionalismo da política como tradução se concentra na tentativa de tornar algumas políticas específicas universais e "re-transcrever" (VENN, 2006, p. 82) práticas socioeconômicas, administrativas e culturais existentes dentro de seu idioma. Não há nada de novo no movimento de ideias, planos institucionais, discursos e reivindicações de conhecimento entre e através dos locais, escalas e atores. Entretanto, nos últimos trinta anos e, particularmente na Europa Central e do Leste no período de transição desde 1991, estes processos se intensificaram.

O espaço impede um exame detalhado da abordagem dominante, objetivista da transferência de políticas, que se construiu desde os primeiros trabalhos do movimento internacional de ideias e práticas, utilizando conceitos como difusão de lições aprendidas de políticas (ver BENNETT, 1991; ROSE, 1991; HULME, 2004). A abordagem tem se desenvolvido, em particular, através de autores como Dolowitz e Marsh, que definem transferência de políticas como:

O processo pelo qual o conhecimento sobre políticas, arranjos administrativos, instituições e ideias de um sistema político (passado ou presente) é usado no desenvolvimento de políticas, arranjos, instituições e ideias em outro sistema político. (DOLOWITZ; MARSH, 2000, p. 5).

Em nossa visão, sua lista de questões-chave, constituída pelas seguintes questões: "Por que os atores se envolvem na transferência da política? Quem são os atores principais envolvidos no processo de transferência da política? O que é transferido? De onde são tiradas as lições? Quais são os diferentes graus de transferência? O que restringe ou facilita o processo de transferência da política? E como está o projeto de transferência da política relacionado ao "sucesso" ou fracasso da política? (DOLOWITZ; MARSH, 2000, p. 8)", parece de alguma forma linear, simplista e finalmente, normativa. 
Nossa maior preocupação, no entanto, é que a ideia de transferência engloba muito menos do que é importante no processo do que a de tradução. Como Yanow (2004, p. 15) sugeriu:

Traduzir não é a mesma coisa do que transferir conhecimento. A transferência sugere uma objetificação ou co-modificação do conhecimento, extrapolado de seu contexto, com o tradutor servindo como mero condutor ou canal através do qual o significado simplesmente passa. Até mesmo este modelo simples de transferência de conhecimento, entretanto, incorpora o problema do ruído - uma distorção do significado original - que reconhece a probabilidade do significado alterado [...].

O ruído e a mediação, distorção e recriação do conhecimento transferido, é crucial, e aponta para uma das contradições de um entendimento universalista tanto dos processos políticos quanto da transferência de políticas por um lado, e das particularidades culturais, políticas e sociais de seus diversos significados, interações, consequências e resistências por outro. A tabela 1 ilustra os diferentes registros ou vocabulários dos dois conjuntos de literatura.

Enquanto a literatura dominante sobre transferência de políticas, com sua ontologia realista, vê a política tanto na origem quanto no contexto receptor como uma realidade estável, pré-existente e inconteste, e a transferência como um processo mais ou menos linear, uma sociologia da tradução trabalha com uma estrutura muito mais fluida e dinâmica. Para os estudiosos que usam a sociologia da tradução:

A política não existe em algum outro lugar de forma acabada, mas é produzida no ato da transferência. A política não está disponível para ser olhada e aprendida, mas é produzida o ato de olhar. A política é o resultado de uma série de comunicações, não a sua origem. A questão tem a ver com germinação, não com disseminação. (FREEMAN, 2004, p. 2).

Tabela 1 - Diferenças no "vocabulário" da literatura dominante sobre "transferência de políticas" e da sociologia da tradução

\begin{tabular}{l|l}
\hline $\begin{array}{l}\text { Palavras-chave para a literatura } \\
\text { sobre transferência de políticas }\end{array}$ & $\begin{array}{l}\text { Palavras-chave para a abordagem da } \\
\text { sociologia da tradução }\end{array}$ \\
\hline Construção & Desconstrução \\
\hline $\begin{array}{l}\text { Transferência de políticas, difusão, } \\
\text { aprendizagem }\end{array}$ & $\begin{array}{l}\text { Tradução, transferabilidade, deslocamento, } \\
\text { "normalização" }\end{array}$ \\
\hline Mudança nas políticas/estabilidade & $\begin{array}{l}\text { Transformação, hibridismo, fluidez, } \\
\text { reflexividade }\end{array}$ \\
\hline Adaptação, disseminação & Negociação, aprovação \\
\hline "Ajuste adequado" & "do desajuste ao ajuste" \\
\hline Instituições & $\begin{array}{l}\text { Redes de conhecimento, redes de atores, agên- } \\
\text { cia, relações sociais, processos }\end{array}$ \\
\hline
\end{tabular}

${ }^{1}$ Em particular aplicada pelo programa de europeização. 
A partir desta perspectiva, a tradução de políticas vai além da transferência de políticas, uma vez que o mundo não pode ser reduzido a noções binárias de estabilidade versus mudança, ou adaptação versus resistência, determinadas pelo "ajuste adequado" (baseado na distância ou lacuna entre a política original e a política no país receptor). A literatura dominante opera dentro de uma perspectiva que tem uma concepção estreita do poder em termos de pontos de veto institucional ou agentes do veto, e sua habilidade de bloquear a mudança. A maior parte da literatura sobre transferência de políticas adere a um "neo-pluralismo reformulado/recauchutado" no qual as sociedades são vistas como compostas por interesses diversos, com o poder distribuído em várias dimensões (STUBBS, 2005a, p. 71). Ao reconsiderar nosso entendimento do processo de transferência de políticas, a partir do ponto de vista da tradução, argumentaríamos que o processo de transferência de políticas deveria ser visto como uma transformação contínua, negociação e aprovação, por um lado, e como um processo politicamente inserido de deslocamento e mudança (do desajuste ao ajuste), por outro lado.

Enfatizar processos de formação, transformação e contestação implica que a transferência de políticas nunca é um processo automático, sem problemas, tido como certo. Ao contrário, sugere a necessidade de prestar atenção às formas nas quais as políticas e seus esquemas, conteúdo, tecnologias e instrumentos mudam constantemente, de acordo com os locais, significados e agências. Neste sentido, uma sociologia da tradução fornece "uma linguagem pela qual podemos começar a explorar a inter-relação do discurso e da agência" (NEWTON, 1996, p. 731), onde a estrutura social é vista não como um substantivo, mas como um verbo (LAW, 1992), acentuando uma abordagem relacional que enfatiza a heterogeneidade, incerteza, fluidez e contestação.

Um aspecto do entendimento da política como um processo de tradução que ocorre dentro de um espaço transnacional é a noção de "zonas de contato", que envolve "a co-presença espacial e temporal de sujeitos previamente separados por disjunções geográficas e históricas, e cujas trajetórias passa a se cruzar" (PRATT, 1992, p. 6). Uma zona de contato é um tipo de espaço "entre" ou "intersticial", semelhante à noção de Homi Bhabha do "terceiro espaço", que nunca está fixo, mas, ao contrário, está sempre "se tornando" (BHABHA, 1995, p. 208), caracterizado por forças e direções ao invés de formas e dimensões. Pratt sugere que uma perspectiva de zona de contato "evidencia as dimensões interativa e de improvisação dos encontros coloniais tão facilmente ignoradas ou suprimidas por relatos difusos de conquista e dominação" (PRATT, 1992, p. 6-7).

Em outras palavras, as concepções estruturalistas dos trabalhos sobre poder colonial estão presas por muitos dos automatismos da literatura dominante sobre transferência de políticas. Enquanto oferecem, nos termos de Bhabha, a possibilidade de evitar "as políticas de polaridade" (BHABHA, 1995, p. 209), o 
conceito das zonas de contato enfatiza a "co-presença, interação, entendimentos e práticas entrelaçadas, frequentemente dentro de relações de poder radicalmente assimétricas" (PRATT, 1992, p. 6-7) ou, nos termos de James Clifford, "um conjunto de trocas carregado de poder" (PRATT, 1997, p. 192). Na zona de contato, os encontros são raramente, ou apenas raramente, sobre palavras e seus significados, mas são, quase sempre, mais ou menos explicitamente sobre reivindicações, oportunidades, escolhas estratégicas e objetivos, interesses e maximização de recursos. Nas zonas de contato, todos os tipos de interações de negociações complexas ocorrem, em cenários múltiplos, bem como nos bastidores.

É precisamente por esta razão, que, enquanto reconhecemos, nos domínios da política social, alguns aspectos tanto da "ambição homogeneizante do inglêsamericano como linguagem universal" como da "tentativa sistemática do discurso neoliberal de colonização... prática" (VENN, 2006, p. 82), nós permanecemos altamente céticos em relação às noções lineares de intencionalidade e causalidade e, mais importante que isso, críticos às noções de fechamento total. O "Inglêsamericano" é, por si só, um produto complexo de um encontro entre duas tradições, conforme indicado pela necessidade do símbolo "_" ligando as duas palavras, como no caso de "Indochina" ou da linguagem do "Servo-Croata" (HERSAK, 2003, p. 132). Sem dúvida, o "Inglês-Americano" do qual Venn fala é a língua franca do Banco Mundial e do FMI, ambos empregando muito mais cidadãos americanos e britânicos do que de qualquer outra nacionalidade. Mas é esta a linguagem dominante ou hegemônica da União Europeia? Poderse-ia, certamente, argumentar que quaisquer pretensões que a União Europeia tenha de celebrar todas as linguagens dos Estados membros de alguma forma "diferentes mas iguais", algumas são mais iguais do que outras e, enquanto o pluralismo linguístico cresce rapidamente com os novos membros, o inglês está se tornando crescentemente importante.

Entretanto, este é um inglês peculiar da União Europeia cujos códigos e termos são, talvez, mais capazes de serem trocados entre um elaborador de políticas, consultor ou burocrata falante de português e um estoniano do que entre qualquer um deles e um leigo, ou até mesmo um acadêmico não elaborador de políticas, falante nativo de inglês. Enquanto vários dicionários de inglês-croata da União Europeia existem, a palavra ou expressão menos traduzível, de fato, parece ser francesa, a saber: acquis ou acquis communitaire ${ }^{2}$. Na verdade, a preocupação da União Europeia com a "exclusão social", não apenas como conceito, mas a forma pela qual ela é estruturada e discutida, pode levar a uma discussão anterior francesa sobre exclusion sociale e muitos outros conceitos científicos sociais e debates vigente na arena Europeia são muito mais compreensíveis quando

\footnotetext{
${ }^{2}$ Ou aquilo que foi concordado pela comunidade, usado para designar a legislação, atos legais e decisões que constituem o corpo da Constituição da União Europeia. (Nota da tradutora).
} 
suas rotas são rastreadas até os escritos alemães. O termo "benchmarking"3 é um dos mais difíceis de traduzir. $\mathrm{Na}$ verdade, em Croata o termo bencmarkiranje ainda é frequentemente utilizado. Portanto, não há um fechamento total, embora a tendência do inglês dominar esteja lá, e estamos longe de uma diversidade real na qual, digamos, o sloveno ou o polonês venham a ter uma influência além dos limites de suas próprias comunidades linguísticas.

A ideia de neoliberalismo universalizado também é problemática. O projeto neoliberal não é de modo algum imutável, todo poderoso e universal como alguns dos críticos do neoliberalismo sugerem. Nestas linhas, John Clarke argumenta que, enquanto a "globalização neoliberal" é a forma dominante da globalização contemporânea, qualquer tentativa de entendê-la como um "projeto hegemônico" tem que tratar tanto das lógicas e limites do neoliberalismo, quanto das diferentes formas nas/com - e contra - as quais as pessoas e locais vivem o neoliberalismo (CLARKE, 2004, p. 89). Ele se interessa profundamente, portanto, pelos "neoliberalismos ímpares", que variam em espaço e tempo, e são capazes de entrar em "formações populares-nacionais" apenas em e através de alianças, "junções de discursos políticos", que inevitavelmente mudam a forma, e produzem "híbridos, paradoxos, tensões e incompatibilidades", ao invés de "implementações coerentes de um discurso unificado e plano” (CLARK, 2004, p. 94).

As formas de política global são sempre articuladas em lugares e tempos específicos, ou como Collier e Ong (2005, p. 4) diriam, "territorializadas em assembleias" que "definem novas relações materiais, culturais e discursivas". Se, seguindo o trabalho influente de Tickel e Peck sobre o assunto, considerarmos a neoliberalização como um processo, cujos resultados são "contingente e geograficamente específicos - uma vez que eles estão se exercitando de um modo não necessário através de uma paisagem institucional ímpar" (TICKEL; PECK, 2003), então são necessários estudos (etnográficos e antropológicos) da política como tradução como parte de um estudo de "globalizações fundamentadas" explorando "forças, conexões e imaginações" (BURAWOY, 2000, p. 344; ver também Jenkins, capítulo 2).

\section{Apresentação de casos: em direção a uma etnografia reflexiva da reforma da política social}

Este texto é sustentado por um compromisso com a etnografia reflexiva como fornecedora de uma base intelectual, e de algo como um ponto de vista privilegiado, para a análise das políticas como tradução. Este compromisso é menos um tipo de noção ideal de "trabalho de campo intensivo" como um tipo de rito de

\footnotetext{
${ }^{3} \mathrm{Ou}$ "busca das melhores práticas que levem uma empresa à maximização do seu desempenho empresarial". (Nota da tradutora).
} 
passagem antropológico, e mais a noção de etnografia de Willis e Trondman (2000, p. 7, ênfase no original) como uma "apresentação evocativa e em camadas... de aspectos localizados da condição humana a partir de dentro", como um corretivo às explorações altamente teóricas, funcionalistas e estruturalistas. O problema é, como Jeremy Gould sugeriu, "a série de coisas que podemos saber em primeira mão - as coordenadas de tempo e espaço que podemos ocupar fisicamente, mais do que aprender a conhecer bem, dentro do escopo de um projeto de pesquisa ou de uma vida toda - é extremamente estreita”, e as políticas transnacionais ("ajuda" mais geral na formulação de Gould) são "compostas de processos multi-locais, multi-níveis e trans-escalas..." os quais necessitam observação transescala como um "dispositivo de tradução" (GOULD, 2004, p. 283).

Sobretudo, nossa preocupação é reconhecer e dar corpo à necessidade de pesquisar locais alternativos de pesquisa, quebrando algumas das fronteiras entre o papel do pesquisador e outros papéis como do consultor, criador de política, ativista, e similares. É através da flexão e mistura de diferentes posições e perspectivas que somos capacitados a ver a "política" como um movimento constante entre o formal e o informal, as práticas institucionalizadas e as não oficiais, o trabalho escrito e "a realidade". Neste sentido, nosso compromisso com a reflexividade, não obstante as críticas justificáveis de seu "relativismo" e falta de clareza conceitual (LYNCH, 2000) envolve, nas palavras de Marcus, "identificação cognitiva e intelectual entre o/a investigador(a) e seus/suas sujeitos(as) diversamente situados no campo emergente da pesquisa multi-localizada" de forma que o/a etnógrafo(a) esteja localizado(a) "dentro do terreno que está mapeando", que serve para reconfigurar qualquer discussão metodológica que aparente "uma perspectiva vinda de cima ou de lugar nenhum"(MARCUS, 1995).

Como parte disso, sugeriríamos que apresentações de fragmentos de material de pesquisa na forma de ilustrações curtas ou estudos de caso são úteis, não menos porque elas permitem uma representação um pouco truncada, mas não menos inteligível, de uma "etnografia das pessoas" que, seguindo a observação detalhada do participante, representa extratos de "notas de campo, extratos de entrevistas e os textos que os próprios membros dos grupos produzem" (FINE, 2003, p. 41). A etnografia é altamente sensível à questão da construção do significado, que é frequentemente negligenciada nos relatos estruturalistas dos processos políticos. Ela oferece um caminho fora do binário agente-estrutura dentro da ciência social corrente, embora, é claro, a questão de como "escrever" os casos permaneça complexa e contestada. Aqui oferecemos tanto uma etnografia multivocal quanto uma leitura privilegiada de certos encontros com a política a partir de nossa própria experiência e prática. 


\section{Fundos Estruturais na Hungria: da política social à coesão social}

Em 2000, um de nós (NL) estava trabalhando no Ministério dos Assuntos de Família e Sociedade do governo Húngaro como consultora no processo de preparação dos Fundos Estruturais a serem absorvidos pelos programas da política social. Naquela época, não muitos funcionários públicos falavam ou entendiam inglês, e uma vez que os regulamentos dos Fundos Estruturais estavam apenas disponíveis em inglês e francês, aqueles que falavam qualquer das duas línguas principais da União Europeia estavam em uma posição-chave para levar os programas em frente. Também era dada alta prioridade à preparação, porque esta oferecia fundos substanciais para esquemas de políticas sociais geralmente pouco financiados. Entretanto, entender a lógica do Fundo Social Europeu para um país que não tinha uma "cultura de projeto" anterior, e interpretar os tipos de atividades que poderiam ser financiadas pelo fundo, foi imensamente difícil. NL e suas colegas logo entenderam que as creches não são creches, mas "conciliadores da vida familiar e trabalho" (um rótulo contra o qual algumas diretoras de creches protestaram); que integração de gênero é mais do que apenas (re) treinar algumas mulheres desempregadas; que regiões e suas desigualdades são motivo de preocupação, com as recém estabelecidas regiões NUTS II (Nomenclatura de Unidades Territoriais para Estatística), uma escala chave na criação de políticas públicas; e que a noção de coesão social financiada pela União Europeia é significativamente diferente de um entendimento tradicional da política social na Hungria.

Parecia haver um desencontro fundamental entre financiamento elegível e os esquemas de políticas sociais existentes na época. Ao invés de falar sobre necessidades sociais, o Fundo Estrutural queria ver as iniciativas da comunidade, o desenvolvimento social e as ideias inovadoras para promover o emprego, igualdade de gêneros e inclusão social. Entretanto, o emprego não era considerado parte de política social; os elaboradores de políticas não estavam familiarizados com as iniciativas da comunidade; e a "inovação" constituía apenas uma parte muito pequena e fragmentária do orçamento da política social. As atividades centrais da política doméstica (assistência social e benefícios, proteção à criança e serviço social e de instituições) não estavam incluídas como atividades elegíveis, e os domínios previamente marginais da política (tais como gênero, política dos povos Roma ${ }^{4}$, inovação e comunidade ou iniciativas regionais) tornaram-se o centro das atenções. Ainda, antes do final da primeira semana o chefe da NL perguntava: "Mas o que é a coesão social afinal de contas?"

O encontro e o (não necessariamente igual) diálogo das duas estruturas de políticas (o fundo estrutural da União Europeia e a política social húngara)

\footnotetext{
${ }^{4}$ Povos Roma ou ciganos. (Nota da tradutora).
} 
oferecem um espaço de reflexão. Por um lado, a diferença entre as duas estruturas de políticas resulta em um "esticamento" do entendimento e estruturação da política social na Hungria, e re-emparelha questões tais como política regional e política social; emprego e política social; educação e política social; e assim por diante. Por outro lado, cria novos "centros" e novas "periferias"; encoraja novos ativismos da política (por exemplo, nos programas que promovem questões de gênero ou a integração dos Roma (ou ciganos)), enquanto marginaliza outras agendas; e forja novas redes de políticas ao mesmo tempo que enfraquece outras. Tanto permite quanto delimita o ativismo dos atores políticos. O processo de estiramento é flexível e aberto, e por causa da falta de compreensão dos conceitos da "União Europeia", as agências, tais como ministérios, um grande espaço de manobra e de reivindicação.

Porém, ao mesmo tempo, os significados só podem funcionar com base nas memórias políticas prévias. Este é o espaço da política onde nada pode ser subestimado e nada parece se ajustar à dicotomia dos estudos clássicos entre mudança política e estabilidade. Tudo está mudando, ainda assim, ao mesmo tempo, a resistência à mudança prevalece e as possibilidades são limitadas. Novos discursos, conceitos, ideias e estruturas políticas emergem; ainda, neste processo intensificado de criação de significado, criação de sentido, a institucionalização destas ideias só pode ser limitada. A experiência de NL no ministério estruturou a "política" e o "processo político" como um constante quebra-cabeça, onde os significados nunca se assentam em uma entidade estável, mas ao invés disso são constantemente contestados, desafiados e, portanto em mutação. Alguns imaginários são totalmente rejeitados, alguns se chocam em barreiras institucionais, e outros são resgatados como discurso político, em um contexto muito fluido. É por isso que as abordagens dinâmicas e orientadas aos processos são tão cruciais para quaisquer reivindicações em direção do entendimento das políticas na prática.

\section{"Projeto de Reforma e Proteção Social" da Croácia}

Em abril de 2002, o primeiro encontro dos principais participantes do Banco Mundial, do Departamento para o Desenvolvimento Internacional do Reino Unido e do projeto de proteção social financiado pelo governo japonês, aconteceu na sala de conferências do Ministério do Trabalho e Assuntos sociais em Zagreb. Um de nós (PS) tinha sido recrutado diretamente pelo Departamento para o Desenvolvimento Internacional para fazer parte da equipe de "serviço social", uma das não menos de nove equipes ou empresas de consultores contratadas para trabalhar em um plano abrangente para as reformas, incluindo equipes de assistência social, trabalho e emprego; questões fiscais e descentralização; reforço administrativo; informática e questões de bancos de 
dados; monitoramento da pobreza; bem como a liderança geral das equipes e da equipe de recursos local.

A suposta importância da ocasião, com apresentações pelo ministro responsável, o Secretário de Estado encarregado da liderança das reformas, os membros da equipe do Banco Central e o Líder de Equipe, foi desafiada por uma discussão anterior que PS teve com um político de carreira, o pai de um amigo próximo, que respondeu, sobre o entendimento da natureza do trabalho, "Ah, eu entendo, é um daqueles projetos", antes de polidamente declinar de intervir para acelerar o início do projeto. Rapidamente, divisões e discordâncias começaram a aparecer entre as equipes de consultores. Um colega Croata, professor de política social na Universidade de Zagreb, pesquisou os consultores estrangeiros e notou a massiva super-representação dos consultores britânicos e americanos e perguntou: "Não tem alguém da Holanda aqui?"

O líder da equipe, em sua segunda visita a Zagreb, rapidamente segregou os colegas Croatas, e alguns dos consultores estrangeiro, ao insistir em explorar os objetivos do projeto dentro de uma matriz de estrutura lógica, na verdade, proferindo uma palestra muito longa, grandemente incompreensível e certamente desnecessária sobre as virtudes da abordagem. Pelo meio caminho, as relações estavam se deteriorando com uma equipe já demitida por ter submetido um trabalho considerado de pouca qualidade e atrasado. Os consultores discordavam constantemente com relação aos contornos da reforma no contexto de uma mensagem clara do Secretário de Estado sobre a importância de advogar uma mudança "radical", e uma mensagem igualmente clara dos funcionários públicos de carreira que nada daquilo deveria, ou poderia ser desenvolvido.

O líder da equipe foi demitido antes do final do projeto, com o relatório final compilado pela equipe fiscal e de descentralização, com mais capacidade para gerenciar suas relações informais com os principais interessados locais em parte através de suas fortes ligações tanto com o USAID quanto com o Ministério das Finanças Croata, defendendo as receitas "divulgadas" para a reforma da proteção social. Nenhuma das reformas foi implementada embora, algum tempo mais tarde, um acordo de empréstimo foi assinado entre o Banco Mundial e o Ministério de Saúde e Bem Estar Social baseado, frouxamente, em algumas das medidas propostas.

O caso apresentado mostra a fragilidade das discussões sobre o conteúdo da política no contexto das modalidades de projetos e os processos problemáticos de falta de comunicação sistemática em uma zona de contato projetada. Logo se tornou claro que aquelas equipes que conseguiam gerenciar os relacionamentos com os principais envolvidos conseguiam mais. Algumas vezes, a parte principal disto, entretanto, era a habilidade de transformar as notas das 
discussões de grupo em apresentações de PowerPoint educadas ou resumir as discussões das oficinas participativas de forma que privilegiassem uma opção de reforma sobre as outras. As questões de linguagem eram importantes pois, na verdade, um estilo de apresentação inglês-americano (preferência dada à lista de pontos) chocava-se com um estilo Croata mais retórico. As complexidades transnacionais de comunicação se chocavam e interagiam com diferenças baseadas em perspectivas disciplinares; tendências políticas; e memórias e experiências anteriores. De muitas formas, as tecnologias de apresentação e, até certo ponto, as tecnologias de envolvimento (HAAHR, 2004), em termos de certas "oficinas participativas" construídas, vieram a dominar os julgamentos tanto de qualidade do trabalho produzido, quanto suas tendências ideológicas ou políticas. Aspectos que ecoavam no primeiro caso, as possibilidades de mudança e as limitações de mudança coexistiam, com uma expansão da variedade de repertórios disponíveis, conceitos e ideias emergentes, mas com coerência limitada em termos de suas inter-relações e sem perspectivas imediatas de sua institucionalização.

\section{Conclusões}

Beck e Lau (2005) em seu último manifesto pela "modernidade reflexiva" argumentam que estamos testemunhando uma transformação contemporânea onde o dualismo, e o "princípio ou isto/ou aquilo", da primeira modernidade é substituído pelo princípio "isto/e aquilo" na segunda modernidade ou modernidade reflexiva. Neste processo, juntamente com a derrubada de fronteiras e distinção entre categorias, "não é mais possível retornar ao tentado e testado, geralmente recursos científicos de racionalização, uma vez que mesmo estes se tornaram ambíguos e incertos" (BECK; LAU, 2005, p. 527). Nesse processo, que para Beck e Lau representa a transformação não contínua das instituições básicas, a política e suas reivindicações e processos de criação de significado, tem um papel crucial.

Neste texto, argumentamos que as políticas não são processos simplesmente lineares, racionalmente construídos. Ao contrário, elas são processos complexos, múltiplos e fluidos de produção de conhecimento, criação de significado e criação de reivindicações que acontecem em espaços múltiplos, inclusive transnacionais. A partir de nossa própria experiência na reforma da política social na Europa Central e do Leste, nós enfatizamos e ampliamos quatro questões cruciais para nossa reconsideração da política: o papel da linguagem; a problemática da transferência da política; a importância de pesquisar locais alternativos ou incomuns; e as questões metodológicas em torno de como o conhecimento sobre os processos políticos são produzidos, através da etnografia reflexiva e da pesquisa multi-locais. 
No contexto da transformação da política na Europa Central e do Leste, a linguagem e, como resultado, os significados, não podem ser desconsiderados. As representações linguísticas estão mudando constantemente e radicalmente, com novos conceitos e discursos emergindo e se reinscrevendo. Além disso, a influência transnacional sem precedentes que acompanha e estrutura esta transformação produz um encontro ou uma colisão entre as linguagens local e transnacional, juntamente com as representações, reivindicações e normas implicadas. A linguagem, então, torna-se um local importante para a resistência política e a contestação. Até certo ponto, a linguagem se torna um local para um processo de exclusão/inclusão dependendo se os variados atores da política são capazes ou querem falar a linguagem dominante, seja ela inglês-americana, o inglês da União Europeia ou outro.

A multiplicidade das linguagens, significados, representações, reivindicações e normas no espaço da política social transnacional evidencia questões importantes em torno das práticas de tradução. Neste texto argumentamos que as transferências de políticas são práticas culturais, políticas e sociais complexas e, como tal, estão longe de serem processos mecanicistas, de cima para baixo e exclusivamente formais. Ao contrário, as questões críticas de distorções, deslocamentos, negociações, e como resultado, de transformação, precisam ser tratadas. As práticas de tradução são sempre plurais e múltiplas e uma vez que nossos casos são tanto sobre confusão e surpresa quanto sobre dominação e resistência, nós contestamos o fechamento completo que as principais narrativas da hegemonia neoliberal geralmente parecem sugerir (ver CLARKE, 2004 para uma crítica deste tipo de teorização). A alegoria da tradução busca enfatizar as alternativas e processos de re-transcrição, que produz histórias, vozes muito diversas e, como resultado, significados e práticas nos processos políticos. A tradução também é uma estrutura dinâmica para capturar a fluidez dos processos políticos, com ênfase na constante (re)construção de questões, discursos, e redes de atores, como parte de uma agência humana real.

Finalmente, quaisquer tentativas de reconsiderar a política precisam tratar de questões metodológicas. Para desdobrar práticas de tradução complexas, nós argumentamos que uma estrutura mais dinâmica e aberta é necessária para capturar a complexa interação de discursos e práticas de base, escolhas conflitantes e pressões, entre o "político" e o "técnico", e na verdade a metamorfose dos atores-flexíveis, locais, escalas e espaços que se cruzam. Na verdade, novos conceitos híbridos, termos e novas perspectivas teóricas são necessárias para entender importantes fragmentos deste processo complexo de transformação. Isto sugere a necessidade de reconceitualizar a política, as instituições, e os contextos. Certamente, as implicações mais amplas desta abordagem precisam ser desenvolvidas em termos de personalidades múltiplas, não mais necessariamente 
privilegiando ou a nação-estado ou o complexo estabelecimento da "transição" como nestes casos. Muitos problemas permanecem, não menos em termos da localização do observador reflexivo e os perigos de exagerar a natureza criativa das interações entre os agentes. Há muito a recomendar para a abordagem da tradução, entretanto, ela é tão digna de exploração quanto parte de uma etnografia reflexiva emergente das políticas, em geral, e da política social, em particular. $\mathrm{O}$ desafio não é menos do que a necessidade de reconfigurar os entendimentos do processo político, transformando nossos próprios vocabulários em torno dele e, finalmente, produzindo novas formas de conhecimento que tenham implicações teóricas e práticas significativas.

\section{Referências}

BECK, U.; LAU, C. Second modernity as a research agenda: theoretical and empirical explorations in the 'meta-change' of modern society. The British Journal of Sociology, v. 56, n. 4, p. 525-557, 2005. DOI: 10.1111/j.1468-4446.2005.00082.x

BENNETT, C. J. How states utilize foreign evidence. Journal of Public Policy, v. 11, n. 1, p. 31-54, 1991. DOI: 10.1017/S0143814X0000492X

BHABHA, H. Cultural diversity and cultural difference. In: ASHCROFT, A. et al. (Eds.). The post colonial studies reader. London: Routledge, 1995. p. 206-209.

BOURDIEU, P.; WACQUANT, L. An invitation to reflexive sociology. Chicago: Polity Press, 1992.

BURAWOY, M. Grounding globalization. In: BURAWOY, M. et al. (Eds.). Global ethnography: forces, connections and imaginings in a postmodern world. Berkely: University of Caliornia Press, 2000. p. 337-350.

CALLON, M. Some elements of a sociology of translation: domestication of the scallops and the fishermen of St Brieuc Bay. In: LAW, J. (Ed.). Power, action and belief: a new sociology of knowledge? Sociological Review Monograph 32. London: Routledge and Kegan Paul, 1986. p. 196-234.

CLARKE, J. Changing welfare, changing states: new directions in social policy. London: Sage, 2004.

What's culture got to do with it? Paper presented to Research Seminar Anthropological Approaches to Studying Welfare, University of Aarhus, Denmark, 16-18 November, 2005.

COLLIER, S.; ONG, A. Global assemblages, anthropological problems. In: COLLIER, S.; ONG, A. (Eds.). Global assemblages: technology, politics, and ethics as anthropological problems. Oxford: Blackwell, 2005. p. 3-21.

DOLOWITZ, D. P.; MARSH, D. Learning from abroad: the role of policy transfer in contemporary policy-making. Governance: An International Journal of Policy and Administration, v. 13, n. 1, p. 5-23, 2000. DOI: 10.1111/0952-1895.00121 
FINE, G. Towards a peopled ethnography: developing theory from group life. Ethnography, v. 4, n. 1, p. 41-60, 2003. DOI: 10.1177/1466138103004001003

FISCHER, F. Reframing public policy: discursive politics and deliberative practices. Oxford: Oxford University Press, 2003.

FREEMAN, R. Research, practice and the idea of translation. Consultation paper, University of Edinburgh, 2004. Disponível em: <http://www.pol.ed.ac.uk>.

GEBHARDT. Introduction to part III. A critique of methodology. In: ARATO, A.; GEBHARDT, E. (Eds.). The essential Frankfurt School reader. New York: Continuum, 1982. p. 81-95.

GOULD, J. Positionality and scale: methodological issues in the ethnography of aid. In: GOULD, J.; SECHER MARCUSSEN, H. (Eds.). Ethnographies of aid: exploring development texts and encounters. Roskilde University IDS Occassional Paper 24, 2004. p. 263-290.

Timing Scale and Style: capacity as governmentality in Tanzania. In: MOSSE, D.; LEWIS, D. (Eds.). The aid effect: giving and governing in international development. London: Pluto, 2005. p. 65.

HAAHR, J. H. Open co-ordination as advanced liberal government. Journal of European Public Policy, v. 11, n. 2, p. 209-230, 2004. DOI: 10.1080/1350176042000194403

HERBERT-CHESHIRE, L. Translating policy: power and action in Australia's country towns. Sociologica Ruralis, v. 43, n. 4, p. 454-473, 2003. DOI: 10.1046/j.1467-9523.2003.00255.x

HERSAK, E. Globalization and the Croatian code. In: MESTROVIC, M. (Ed.). Globalization and its reflections on (in) Croatia. New York: Global Scholarly Publications, 2003. p. 131148.

HOLMES, D.; MARCUS, G. Cultures of expertise and the management of globalization: toward the re-functioning of ethnography. In: ONG, A.; COLLIER, S. (Eds.). Global assemblages: technology, politics and ethics as anthropological problems. Oxford: Blackwell, 2005. p. 235-252.

HULME R. Borrowing or learning? The role of policy transfer in assessing the impact of American ideas on British social policy. Paper presented to GASPP Seminar The Rise and Fall (?) of the International Influence of US American Social Policy. McMaster University, Canada 10-11 September, 2004. Disponível em: <http://www.gaspp.org/ seminars/papers/7/rhulme.pdf $>$.

INNES, J. Knowledge and public policy. 2. expanded edition. New Brunswick: Transaction Books, 2002.

IVEKOVIC, R. Transborder translating. Eurozine, 14 jan. 2005. Disponível em: <www. eurozine.com/articles/2005-01-14-ivekovic-en.html>.

KIBBERD, D. Inventing Ireland: literature of the modern nation. London: Vintage Press, 1995.

LATOUR, B. The power of association. In: LAW, J. (Ed.). Power, action and belief: a new sociology of knowledge? London: Routledge, 1987. p. 262-280. 
Reassembling the social: an introduction to actor-network-theory. Oxford: Oxford University Press, 2005.

LAW, J. Notes on the theory of the actor-network: ordering, strategy, and heterogeneity. Systems Practice, v. 5, n. 4, p. 379-393, 1992. DOI: 10.1007/BF01059830

LENDVAI, N.; STUBBS, P. Translation, intermediaries and welfare reforms in south eastern Europe. Paper prepared for the 4th ESPANET conference: Transformation of the welfare state: political regulation and social inequality, Bremen, 21-23 September, 2006.

LOOMBA, A. Colonialism/Postcolonialism. London: Routledge, 1998.

LYNCH, M. Against reflexivity as an academic virtue and source of privileged knowledge. Theory, Culture, Society, v. 17, n. 3, p. 26-54, 2000. DOI: $10.1177 / 02632760022051202$

MacCLANCEY, J. Introduction: taking people seriously. In: MacCLANCEY, J. (Ed.). Exotic no more: anthropology on the front lines. Chicago: University Press, 2002. p. 1-14.

MARCUS, G. Ethnography in/of the world system: the emergence of multi-sited ethnography. Annual Review of Anthropology, v. 24, n. 1, p. 95-117, 1995. DOI: 10.1146/ annurev.an.24.100195.000523

MONACI, M.; CASELLI, M. Blurred discourses: how market isomorphism constrains and enables collective action in civil society. Global Networks, v. 5, n. 1, p. 49-69, 2005. DOI: 10.1111/j.1471-0374.2005.00107.x

NEWTON, T. Agency and discourse: recruiting consultants in a life insurance company. Sociology, v. 30, n. 4, p. 717-739, 1996. DOI: 10.1177/0038038596030004006

NIRANJANA, T. Siting translation: history, post-structuralism and the colonial context. Berkeley: University of California Press, 1992.

O’MALLEY, P. Indigenous governance. Economy and Society, v. 25, n. 3, p. 310-326, 1996. DOI: $10.1080 / 03085149600000017$

PRATT, M. Imperial eyes: travel writing and transculturation. London: Routledge, 1992.

ROSE, R. What is lesson-drawing? Journal of Public Policy, v. 11, n. 1, p. 3-30, 1991. DOI: 10.1017/S0143814X00004918

RUSTIN, M.; FREEMAN, R. Introduction: welfare, culture and Europe. In: CHAMBERLAYNE, P; COOPER, A; FREEMAN, R; RUSTIN, M. (Eds.). Welfare and culture in Europe. Towards a new paradigm in social policy. London: Jessica Kingsley, 1999. p. 1-31.

SAKAI, N. Translation. Theory, Culture, Society, v. 23, n. 2-3, p. 71-78, 2006. DOI: $10.1177 / 0263276406063778$

SCOTT, J. W. A networked space of meaning? Spatial politics as geostrategies of European integration. Space \& Polity, v. 6, n. 2, p. 147-167, 2002. DOI: 10.1080/1356257022000003608

SHORE, C.; WRIGHT, S. Policy: a new field of anthropology. In: SHORE, C.; WRIGHT, S. (Eds.). Anthropology of policy: critical perspectives on governance and power. London: Routledge, 1997. p. 3-39. 
STONE, D. Policy paradox: the art of political decision making. Revised Second Edition. New York: WW Norton and Company, 2002.

Public knowledge in the global agora. In: KRIZSAN, A.; ZENTAI, V. (Eds.). Reshaping globalization: multilateral dialogues and new policy initiatives. Budapest: Central European University Press, 2003. p. 41-62.

STUBBS, P. Stretching concepts too far?: multi-level governance, policy transfer and the politics of scale in South-eastern Europe. South Eastern European Politics, v. 6, n. 2, p. 66-87, 2005.

TICKELL, A.; PECK, J. Making global rules: globalisation or neoliberalisation? In: PECK, J.; YEUNG, H. W-C. (Eds.). Remaking the global economy: economic-geographical perspectives. London: Sage, 2003. p. 163-181.

VENN, C. Translation: politics and ethics. Theory, Culture \& Society, v. 23, n. 2-3, p. 82-84, 2006. DOI: $10.1177 / 026327640602300214$

WEDEL, J. R. US foreign aid and foreign policy: building strong relationships by doing it right! International Studies Perspectives, v. 6, n. 1, p. 35-50, 2005. DOI: 10.1111/j.15283577.2005.00192.x

WILLIS, P.; TRONDMAN, M. Manifesto for ethnography. Ethnography, v. 1, n. 1, p. 5-16, 2000. DOI: $10.1177 / 14661380022230679$

YANOW, D. How does a policy mean? Washington D. C.: Georgetown University Press, 1996.

Translating local knowledge at organizational peripheries. British Journal of Management, v. 15, n. 1 (special issue), p. 9-25, 2004. DOI: 10.1111/j.1467-8551.2004.t011-00403.x

Recebido em 05/11/2011

Aceito em 20/12/2011 